Submitted version - not for citation. See published article at http://www.springer.com//2/AVHG3jMSAgfPWjhryHL9

\title{
MAKING SPACE FOR CONSUMING PRACTICES
}

\begin{abstract}
This empirically driven paper is about workplace learning with specific focus on the 'work' of consuming practices. By consuming we refer to the eating, and the drinking, and (at times) to the smoking that workers, in most organisations, do on a daily basis. Indeed, it is the quotidian nature of consuming, coupled with its absence from workplace learning research that make them noteworthy practices to explore. In using the term practice we draw on the recent tranche of practice based theorisations: notably Theodore Schatzki $(1996,2005,2006)$ and Silvia Gherardi $(2001,2006,2009)$. The paper frames consuming practices as 'dispersed' (general) practices and, illustrated through empirical data from multiple projects, we progressively outline how these contribute to the learning of 'integrative' (specialized work) practices. Our overall aim is to (re)position consuming practices from prosaic, to having much relevance for research on workplace learning.

\section{Introduction}

Workplace learning research has matured over the past three decades. From its earlier focus on the acquisition of knowledge and skills, to more recent developments (following Sfard, 1998) where participation and becoming are utilised as apt metaphors, workplace learning remains an important area of research. Despite shifts in thinking, there also remains an eagerness to make visible workplace learning in all its manifestátions (e.g. Fenwick and Field, 2014). Some researchers look to the workplaces thenselves. For instance, Billett's work on affordances (2001) and workplace curriculum (2011) drew our attention to the situated nature of workplace learning. Another focus has been to look toward work activity itself to inform accounts of learning (e.g. Engeström, 2001). Recent developments have seen practice based theories emerge as a popular heuristic to inform eontemporary studies of workplaces, and professional learning. Part of the appeal of these is that attention is shifted away from the individual to the actual practices of -workers. Given that practice theories come under the broad auspice of socio-material theories (e.g. Fenwick, Edwards \& Sawchuck, 2011), they also invite us to look anew the non-human aspects of practice as well, including spatial elements.
\end{abstract}

Like others, we have looked to actual work to inform our own accounts of everyday learning at work: more recently finding practice theorisations helpful. Indeed we used these in our investigations of the learning dimensions of site-walks (ANON 1), clinical handovers (ANON 2) and winemaking (ANON 3). Of relevance here is that these practices are germane to the actuat work of those involved: i.e. engineers, nurses and winemakers. In Schatzkian ternis, we understand these practices as work-specific integrative practices (Schatzki, 1996, p. 92) However, integrative practices are not the only practices at work: more generalized or dispersed (Schatzki, 1996, p. 92) practices also unfold. These are the practices that are not germane to any type of work but are more generalised - they can be seen in almost all work sites: even if not part of actual work itself. It is here that we position consuming practices and yet, distinguishing these dispersed practices from integrative ones we also note a relationship between them.

In this paper we are particularly interested in consuming practices and by this we mean eating, and drinking, and (at times) smoking carried out by workers. Of importance here is the ubiquitous nature of these practices leading to the likelihood that most workers undertaking them on a daily basis. That is, consuming practices are pervasive: given human bodies require sustenance it is likely that most workers potentially consume in and around their workplaces every day. Thus, we agree with Briner and Sturdy (2008, p. 908) who contend that eating and drinking in and around organisations takes place on a daily basis. Yet 
Submitted version - not for citation. See published article at http://www.springer.com//2/AVHG3jMSAgfPWjhryHL9

despite their widespread nature, these practices are rarely the object of workplace learning research. If eating or drinking is mentioned, it is typically superfluous to any central argument: background detail at most. In this paper we have set ourselves the task of featuring these practices and their relevance to workplace learning.

We note that it is almost a decade since an interviewee in a workplace learning research study described to one of the current authors how the call of 'Who wants tea?' was local code for 'There's a problem, lets meet in the tea-room to discuss it' (ANON 4, 2006, $\mathrm{p}$. 325). At the time it was the everyday learning involved in the workgroup's meeting in the tearoom that captured our attention - with tea drinking relegated to contextual detail. Ten years later, the significance of the comment resonates more strongly - particularly given how similar accounts were continually echoed in subsequent workplace learning research projects. Our own emergent learning lead us to position consuming practices through this paper, as very much implicated in workplace learning - not the stuff of mere background or context. To do this we draw on data from multiple studies of various types of organisations to illustrate the potential work of consuming practices in regard to workplace learning. Wepropose that the generality and prevalence of consuming practices renders them more interestingthay they may first appear. Indeed, it is the combination of (1) our interest in workplace learning, and (2) the pervasiveness of consuming and (3) consuming practices' simultaneous absence in workplace learning research that provides initial warrant for this paper. Through the secondary analysis (Heaton 2008) of qualitative data derived from three separate studies we illustrate a relationship between consuming and learning, and in doing so position consuming as having more relevance to workplace learning than generally supposed. A secondary aim is to whet appetites and invite further research. An associated aim is to draw on a range of conceptual resources that might frame future research?

The paper begins by providing a brief background of research literature that focuses on consumption or consuming in organisations. We then introduce the three studies that prompted our interest in consuming practices and learning, and that provide our empirical examples. Next, is a discussion of the complex spatiality of place, space and identity, proposing that consuming (and learning) practices are 'bundled' (Schatzki 2006) - and shift relational boundaries for those whpparticipate in them. We offer some examples from the data linking consuming and learning providing illustrative examples from the data in spaces at work, alongside work and beyond work. Finally, we conclude by pointing to some implications for learning at wotk, cautioning that while (integrative) consuming practices coexist with work practices they do not automatically facilitate workplace learning as they intersect in situ. The paper concludes by suggesting that the connection between these would be a fruitful direction for future workplace learning research.

\section{Consuming and learning literature}

In the paper wa duse the word 'consuming' rather than 'consumption'. This is because the term consumption is used in a variety of very specific ways and from an assortment of standpoints. For instance, consumption, in economics, is a central concept loosely understood as the purchase of goods and services (cf Friedman 1957; Keynes \& Moggridge 1979). For all manner of Marxists the word consumption is closely linked to that of production: emphasis is given to discrepancies between those who produce and those who consume in capitalist society. In medicine the term has been used to name what we now understand as tuberculosis. Its use in cultural studies (du Gay 1996) sees the meaning deployed differently again, as does its take up in more recent socio-material studies (Shove, Trentmann \& Wilk 2009). We acknowledge that consuming can mean 'using up', which may link it somewhat with meanings of consumption outlined above. However, it can also simply mean 'eating or drinking' and it is this sort of consuming we are referring to. Furthermore, just as consumption is coupled with additional terms like production and/or sustainability to illuminate particular ideas, we couple consuming with 'practices'. Coupling it this way qualifies the practices we are interested in (i.e. eating and drinking practices): consuming 
Submitted version - not for citation. See published article at http://www.springer.com//2/AVHG3jMSAgfPWjhryHL9

practices. We further understand that defining our interest in this way limits our analysis. For instance, du Gay's (1996) accounts of the 'consuming organisation' and of 'entrepreneurial selves' have potential for extending the work of consuming practices and those who carry them out: likewise, several contributors to Shove et al.'s (2009) edited volume promise interesting lenses through which to view eating and drinking at work. While we draw on these only selectively, we do so in appreciation that yet more is to be done.

In terms of what is consumed in consuming practices there is also a diversity of related literature. For instance, Harbers, Mol and Stollmeyer (2002) draw attention to the importance of ethnographies of daily care in nursing homes through a discussion of the sociomateriality of food, or of chocolate more specifically. A growing number of scholars are also becoming interested in food related studies and food pedagogies (Flowers and Swan, 2009; Warner et al., 2013). While many of these studies also feature learning it is what is being learned that defines them as useful or not to our purposes here. For instance, in some of the latter cases the object of learning is what is being consumed (e.g. food, food preparation, sustainability of food sources etc.), whereas other instances align more to du Gay's (1996) version of consumption in which the consuming of particular foodstuffs associate those who consume with particular ethnic, classed and/or gendered identities.

Consuming practices are the focus in some studies of work an wotkplaces: albeit without explicit links to learning. For example, in a special edition of Human Relations, various authors draw attention to the effects of the intake of food and dynk on organisations, organisational practices and identities. Parker (2008) writes of the important 'work' involved in creating a sense of belonging to an organisation, suggesfing in many organizations, food often seems to be symbolically deployed as a representation of community' (p. 989). FloresPereira, Davel, and Cavedon, (2008) explore the drinkirg of beer and the embodiment of organisational culture and suggest organisational culture is a perceptual-embodied experience and beer drinking is an example of this experience(p. Y023). Brewis and Grey (2008) examine the moral and scientific discourses regulating smoking in workplaces. Similarly, with a focus on applied linguistics, Eggins and SYade (2004) analyse workers' talk while eating lunch in their workplace, demonstrating this space as one where solidarity and trust are constructed and built up. Their emphasis is on casual conversation/informal talk in workplaces that occurs at lunch or coffee breaks offering an insight (albeit implicit) into the importance of site-specific social practices surrounding eating. Looking across this literature it is easy to imagine that some learning may also be taking place alongside the consuming. However to imagine this requires understandings of learning beyond those framed in traditional cognitive and behavioural terms. Various thinkers (Fenwick, Edwards \& Sawchuck, 2011; Hager 2008; Hager \& Hodkinson 2011; and Sfard 1998) have extended notions of learning to include ideas on participation and becoming. With these understandings, the examples above could say more about workplace learning than currently offered. While admittedly the authors' foci are elsewhere, there remain few examples that explicitly link consuming and learning. A more relevant exception is ANON 5's (2006) exploration of the relationship between everyday learning and consuming in terms of how consuming as a metaphor for learning promises new insights for researchers into everyday learning.

Our paper builds on this literature. Although, our aim is more modest than that made by Pina $e$ Cunha et al (2008 p. 957) who optimistically suggest the challenges of the organised world could be approached through the study of food. Rather, we limit the challenge to exploring workplace learning through a lens of consuming practices. We suggest that such an exploration offers insights into workplace learning through a meshing of work and private domains of practice with a specific focus on how this mix impacts on workers' social relationships, or 'relatings' (Kemmis 2009, p. 23). In doing this, we situate our analysis of consuming practices through dimensions that practice theory attends to by exploring its sociomaterial considerations. Consuming practices encapsulate social and spatial (material) happenings that take place in-between everyday work tasks, ones that are ostensibly in the 
Submitted version - not for citation. See published article at http://www.springer.com//2/AVHG3jMSAgfPWjhryHL9

private domain yet enacted at, alongside and even beyond work. For example, taking a lunch break is an occasion where workers are not carrying out their substantive duties, yet they are not necessarily unencumbered by their workplace duties or relationships as workers. In addition, consuming practices are usually located in the in-between of the work space and private space such as in tea/lunch rooms (ANON 5 2006). This socio-spatial shift means that who workers are (i.e. their relatings) whilst engaged in consuming practices might also be understood as in-between or hybrid. Overall, following Pina $e$ Cunha et al (2008) and Eggins and Slade (2004), we posit that consuming practices afford learning opportunities via the kinds of talk these occasions make possible.

\section{Research projects, sites and methods}

Prompted by an increasing awareness of consuming practices noticed across our own studies, this paper revisits empirical data from three such studies. This section introduces our selected studies, the sites involved and the methods employed. One or more of the authors vere involved in each project. The studies are presented in chronological order and, in doing so illustrate our mounting curiosity with consuming practices.

Our first study was an Australian Research Council (ARC) research study concerned with everyday learning at work. Using interview and observational methods the study explored the everyday learning of four different groups of workers (1.e. strategic planners, a human resource department, vocational teachers and unit responsible for sourcing outside training contracts) in a large public sector education and training organisation. Around 50 workers were interviewed, and even more were observed in situ. During analysis of the data it was noticed that food and beverages featured when discussions turned to everyday learning at work (ANON 2006). For example, meal breaks, frorking lunches and even breaks during professional development activities were constructed as not only consuming spaces but also as everyday learning spaces (ANON 2006). Itwas alsothis study where the earlier comment about 'tea drinking' was uttered. A second study investigated workplace learning in relation to particular organisational practices on an organisation's ongoing effectiveness. The study aimed to provide a rich account of the fived experiences of workplace practices that facilitate learning, yet are independent of formal training programs and are not explicitly defined in terms of training and education. Four d) fferent organisations were studied: a Community College, a public Utility, a loeal Coyncil and a Vineyard. We analysed organisational documents relating to various workplace practices and observed workers and work teams going about day-to-day work. We also carried out in-depth interviews with over 60 workers from across these organisations. Again, interviewees referred to eating, drinking and smoking as they responded fo questions about work practices and organisational changes. The third and most recen study investigated collective learning. It examined a culturally and linguistically diverse team constituting a non-medical unit of a local health district. Like the previous studies, along with observations and group and individual interviews of the six team members, data collection included analysis of organisational documents and other artefacts. In conducting ethnographic data collection in this study, the role of food in facilitating learningand social cohesion was identified as central to the team in achieving their outreach goals.

While representing a diverse range of actual work sites and forms of work, these studies share three important similarities that lend themselves to a secondary analysis. First, all three explored learning in and for the workplace going beyond learning as a result of formalised educational interventions. Second, each employed ethnographic data collection methods: where participants were encouraged to talk broadly about their work. Third, while none of the studies was specifically about consuming, nor were there questions specifically about consuming practices in the interviews, reference to consuming appeared sufficiently in the data to capture our attention and prompt a closer look at its relationship to learning. These similarities make the studies highly suitable for a secondary analysis (Heaton 2008).

Secondary analysis involves asking new questions of data collected from one or more earlier 
Submitted version - not for citation. See published article at http://www.springer.com//2/AVHG3jMSAgfPWjhryHL9

studies (Heaton 2008). While a common strategy in quantitative studies, it is only recently being utilised in qualitative studies. An advantage of secondary analysis is that efficient use can be made of the increasing volume of qualitative data. In our own case, at least one of the authors was involved in each of the studies. We also add that participants' informed consent in each project does not preclude publications such as this.

In undertaking our analysis we revisited interview data from all three studies for reference to consuming of food, drink, as well as eating and drinking (along with a long list of possible synonyms). This resulted in scores of pages of examples once we also captured the context in which these references were uttered. A second wave of analysis looked at the examples where learning could reasonably be implicated. A number of examples were generated: many of which we 'work with' below in support of our argument for the importance of the relationship between consuming practices for workplace learning.

\section{Connecting consuming and learning practices}

The site of the workplace is central to what transpires and to what is learned there (Hopwood 2014; Gherardi 2006; Schatzki 2005, 2006). In terms of more recent theorisations we can consider workplace learning as progressively coming to know and enact the relational and material practices of a site. Individual workers learn to engage in (social) ways appropriate to a setting as they draw on multiple knowledges in the socio-materiałenvironment (Gherardi 2009). In carrying out their daily activities, workers demonstrate their knowing as a practical accomplishment. They participate by utilising material objects, by engaging in relationships with those they work with and through conducting activities in competent ways (Gherardi 2001). Knowing what to do, and how to be in a work setting therefore can be understood as a social process, involving human, material, aesthetic, ethical and emotive aspects (ANON 2012) following Gherardi (2006). ' $[\mathrm{K}]$ knowledge is embedded in practice ... [it is the] domain where doing and knowing are one and the sarne' (Gherardi 2006, p. xii). With this understanding doing also encompasses consuming (e.g. eating, drinking and smoking) along with the more apparent practices of work.

At its most basic, learning has been traditionally understood as coming to know something new or different (acquifipg knowledge) or being able to do something new or different (developing or acquiting skitls). In our data we saw many examples of this: For instance, we saw workes consuming and learning (to know more about their organisation):

There's a lot of it inyour tea room sort of situation, [...] there's a lot of it, you may be seeing a person about another matter, and you'll finish that discussion and they'll happen to Say Oh did you hear about so and so the other day'? Sometimes it's... it cartbe a bit offa background thing like the safety bulletins and stuff like that. (Public Sector Utility)

We atso saw workers consuming and learning (to $d o$ aspects of their job differently):

... ike customer service training [...] they all come in and I give them afternoon tea and basically we let them have a bitch session about this and that and customers... and then we talk about what can we do to change that and it always reiterates [sic] with my customer service training - 'Remember you're a customer as well, how do you want to be treated'? (Council)

In these first examples we see workers acquiring knowledge (about their organisation) and competences (enacting customer service) while simultaneously consuming. But we want to extend these notions of learning (and consuming) to incorporate newer ideas. The idea of learning as acquiring competence and knowledge has increasingly been seen as limited. Hager and others, following Sfard (1998), are among the forerunners of such a position with their work on learning metaphors (Fenwick, Edwards \& Sawchuck, 2011; Hager, 2008; Hager $\&$ Hodkinson 2011). Each argues traditional learning metaphors are inadequate, and instead advocate for others. Becoming and participation are common among these other metaphors 
Submitted version - not for citation. See published article at http://www.springer.com//2/AVHG3jMSAgfPWjhryHL9

and have gained momentum in contemporary research. This is largely due to their capacity to encompass the ongoing nature of learning and its social and emergent dimensions. For instance, the 'becoming' metaphor recognises workers' continual learning and development of their practice: never fully 'becoming'; whilst the 'participation' metaphor acknowledges learning happening alongside and with others as people go about their work practices: a social practice. In our data we also saw learning and consuming linked with these later understandings. For example, we saw workers consuming and learning 'becoming' new/better workers while undertaking performance appraisals. Such appraisals typically involve some form of discussion and assessment of worker performance. At the Utility, a worker describes how feedback on his performance is provided: '[They] let me know 'Oh that's ...that's worked out' [...] I mean [the boss] and I go for the odd beer and stuff like that'. Here, opportunities for worker development (or becoming) occur through talk over the 'odd beer'. However, we also saw workers consuming and learning (to work together) through participation. Our example here is from the Vineyard where a chef is employed to cook for)all staff in order that 'everybody in the organisation mixes and swaps ideas and spends time together... it will be better for the organisation if we can have people communicating with each other, swapping ideas'.

Our examples thus far illustrate the limitations of traditional metaphorg of learning. Workers not only learn new skills or acquire new competencies, thex also learn how to become new/better workers (i.e. they are becoming) as well as learn hoy to work with others (i.e. participation). Interestingly these four metaphors looselyresemble pillars of learning (learning to know, do, relate and live/work together) identified almost two decades ago (Delors 1996). Furthermore, they draw attention to the linitations of cognitive and behavioural ideas of learning and focus instead on learning as situated, in keeping with practice-based conceptualisations (Gherardi 2006; Schatzk 2006). We notice space and the consuming practice and how the examples above each took place in different arrangements with work and workplaces. The first example oecurred at work in a non-work space, whereas in the second example it was alongside designated work practices. In the third example the utility worker is learning while consuming at a local pub - that is, beyond the workplace. Finally, in the fourth example consuming and learning takes place at work in an eating/drinking space. It is noticing these differences that invites a closer look at the sociospatial aspects of consuming and learning and the relatings of those who consume and learn.

\section{Place, space and relating}

In this section we present, and then indicate how we draw on key conceptual resources of the situated nature of eonsuming and learning before providing further examples from our studies. We add topractice-based perspectives on the relationship between worksites and learning outlined earlier (Hopwood 2014; Gherardi 2006; Schatzki 2005, 2006). We do this to strengthen the role that consuming practices might play in fostering the social aspects of learning as they relate to work. We begin by recapping how place plays a central role for many interested in strengthening and maintaining civil society. For example, in discussions of social capital 'the commons' are the places where important social bonds are created and maintained. Similarly the demise of particular places is lamented because of their value in 'the development and maintenance of community' (Morris 2005, p. 31). Oldenburg (1999) writes of the importance of place in the creation of civil societies and stresses the importance of third places. These third places are differentiated from first places (the home) and second places (the workplace) in that they are informal places where workers 'can connect with others' (Morris 2005, p. 22). Relevant to our discussions, these third places may include cafes, coffee shops, bars and other 'hangouts at the heart of the community' (1999).

Exemplified in the title of his book, Oldenburg's writing is replete with reference to the consuming of food and beverages in these third places (1999). Consuming, itself, however, is positioned as little more than a parallel act alongside the 'real' business of creating and maintaining social relationships made possible through a fixed sense of (third) place. While 
Submitted version - not for citation. See published article at http://www.springer.com//2/AVHG3jMSAgfPWjhryHL9

these discussions of place are helpful in drawing attention to the importance of social relationships, our understandings render place more complex. Place (be it first, second or third) in the work of these researchers, is a kind of stage or set for social action. Oldenberg's notion of third place assumes a neat distinction between home and work, and differentiated from a third place. We suggest such distinct boundaries are less clear. The home office is an example where the boundaries of first and second places are blurred. Similarly, in workplaces there are places such as tearooms or around a coffee machine where the boundaries between first and second places are permeable.

Moving beyond notions of differentiated place to other theorisations of space is helpful when considering consuming practices and workplace learning. Postmodern approaches to space and spatiality are underpinned by an understanding that space is never merely a stage or set, rather it is always socially constructed and thus representationah at the same time as being material. Liminal space and thirdspace are terms coined to theorise notions of space beyond bounded, binaried, two-dimensional or material understandings. Bhabha (1994), in his work on 'location' of culture(s), develops liminal or thirdspace as ambivalent, hybrid spaces that do not separate but rather mediate the mutual exchange and relative meanings of spaces, while at the same time producing tensions and overlaps. Soja (1996; 2001), a cultural geographer who builds on the seminal work of Lefebyre (1991), is also concerned with theorising a thirdspace, calling it lived space, which, for him is a necessary third beyond the modernist binary of perceived (physical)any conceived (mental) space. It is within this thirdspace that there are possibilities of exploring both built and social hybridity, and it is where symbolic use of objects occurs, often expressed as systems of nonverbal symbols or signs. We posit eating, drinking and sunoking as examples of non-verbal symbols (qua practices) that construct thirdspaces. Liminal space has been taken up by a number of researchers in organisational and management studies to describe the organisational spaces where consuming practices are enacted (Briner \& Sturdy 2008; Driver 2008; Parker 2008; Pine $e$ Cunha et al 2008). Timinal space is an in-between space, and it is this latter term used by ANON (2004) to examine the overlaps and synergies arising when food, work and learning are intermingled. The in-between has also been used to describe literal spaces in workplaces where consuming practices take place (ANON 2006).

In each of our research sites, there is a designated material location at work where a variety of consuming practices takes place. Some are lunchrooms, while others are areas with limited kitchen/coffee-making facilities. These places, while having some furniture and appliances similar to kitchens and dining rooms found in private homes, are located within organisations, and assuch do not function as wholly private spaces. They are hybrid spaces simultaneously work and not-work spaces. Solomon et al. (2006) explain:

These spaces are not so work orientated that they can be described as workspaces, nor are they entirely social. The nexus between work and the social, of being a worker and a social being, of engaging in legitimate work and socializing are put forward as rich expanses for everyday learning (p. 3).

As the Writings of Solomon et al. and others (see, for example Edwards \& Usher, 2000) point out, complex identities - which a practice-based approach would conceptualise as 'relatings' - are implicated in these in-between spaces. Rather than notions of fixed, stable or singular identities, the in-between-ness creates shifting, hybrid and multiple identities that blur, at least to some extent and for some time, recognised social and work positions and practices. Solomon et al. (2006) see identities in in-between spaces as transformational and transitional: 'When [workers] enter these spaces they are neither entirely workers nor social beings, but located in between' (p. 11). These understandings have contributed to our developing insights into worker-consumers who appear as both workers and learners. Despite the uncertain and possibly hybrid activities undertaken by workers, there is nothing untoward in this, because in Schatzki's (2006) understanding of the worksite, their co-existence merely reflects the way 'consuming' practices are 'bundled' with 'work' practices. Workers learn to enact both. 
Submitted version - not for citation. See published article at http://www.springer.com//2/AVHG3jMSAgfPWjhryHL9

\section{Learning/consuming at, alongside, and beyond work}

In this section we discuss a range of consuming and learning practices noted across the organisations visited. In revisiting our data, we examine the complex socio-spatiality or sociomaterial practices and the multidimensionality of learning in the worksite. We begin by outlining the complexities of these locations reconfiguring them as hybrid or in-between spaces that construct and/or maintain in-between identities: at work in a designated consuming location while taking a break from work tasks; within the workplace alongside work; and, beyond the immediate workplace.

Most of the examples of consuming practices in our data we characterise as 'at work' where consuming occurs within everyday work practices, but in a distinct consuming location. Our first example comes from the Utility research site, which holds bi-annual Safety Days for its entire staff. These days provide workers with a range of training sessions, Safety inspections of equipment (e.g. gas cylinders, harnesses), as well as a much talked about lunch: 'Safety Days, Safety Day that was purely safety and obviously lunch is a part of if' While the organisation has a large and well-used lunchroom, on Safety Days furniture is brough in to create a large outdoor eating area in the organisation's main depot. When describing Safety Days, some interviewees' comments were limited to the array and amount of food on offer: 'sausage rolls for morning tea... focaccia, wraps and sandwiches with fillings like salads and things like that, which keeps everybody happy'. Yet along with 'keeping everyone happy', the value of Safety Day lunches, how they benefit the organisation, was acknowledged by the senior manager. In particular, he explains why they now use caterers rather than hold their own barbeques:

... because what predominantly happened was, pou're trying to do 100 people, there's 3 or 4 people that are behind the barbeque all the time, then clean up afterwards and do all that work [...] so we said well, I'd like those guys to be part of it [... I'm also trying] to integrate my transmission and distribution people [...] so they talk

Safety Day lunches exemplify a thirdspace or in-between space. Lunches are physically located at work during compulsory Sa ety Days, yet lunchtime is a spatio-temporal context when workers are not performing stbstantive work duties. Furthermore, while the lunch itself appears as downtime in regard to the day's main purpose of ensuring safe work practices, the workers are not completely free from their responsibilities to the organisation to enhance safe working practices. They are also expected to realise the manager's vision of integrating 'transmission and distribution people'. In other words, while engaged in consuming at work, workers are also working toward a less conspicuous organisational objective. A similar vignette was noted at the $V$ ineyard where a worker told us how the lunchroom doubles as a worksite. Another Vineyard worker's comment adds strength to this - particularly when asked whatgoes onthere:

Just normal conversation, you know because we're all now rostered on different days, oh well, you know, this is new, we now have to do it that way. Oh no, I haven't heard of that, I'll ask [Name] what's going on. Or, oh, yeah I've heard of it, you know so that's it. (Vineyard)

Workers in the multicultural health team were explicit about how their designated lunch space was implicated in their learning. Each team member office opened into a shared space. This space included a photocopier along with a fridge and some cupboards equipped with food preparation and coffee making facilities. In the centre of the space was a table - a table central to many discussions of their collective learning. The team started each day with coffee and a chat - they told us what this chat entailed:

We'll have a coffee and often we'll chat generally, 'how's everyone going' [...] but also we'll talk about the day before [and] touch on some work things

Another team member was compelled to justify the team's 'coffee ritual': 
Submitted version - not for citation. See published article at http://www.springer.com//2/AVHG3jMSAgfPWjhryHL9

And we do network, because it's not about wasting time. Some people will think having that morning tea or afternoon tea that we do it - might be, you know - you could be more efficient or effective; that's not actually true, because what you do is network and you do get a lot of things sorted. A good example is when [Name] was starting moving on project and I would have just started; he was saying for example during one of these breaks that he needed to find bilingual professionals and you know if he didn't say it in front of me then I wouldn't be able to say 'I do have two colleagues' because I have worked with clinicians and I know quite a lot of them; and that's how it was sorted out in that morning tea.

Yet team another member adds 'because we're always outside with someone else [and] we want to be connected as a team'. In these examples consuming practices occurred in spaces at work, but were not necessarily spaces where the main work of the organisation occurred.

What is emphasised in each case, is the importance of social connection - of talk and action to reconfigure the lunch-place into a space of sharing, finding out, extending networks, and so on.

Consuming practices occur alongside work as well. Having consumed at dur desks ourselves, we know only too well it is not only pauses in work where consuming takes place. Breakfast meetings, working lunches, lunch or coffee at one's desk, et $C$, are examples of this. During observations, we noticed how food was incorporated into aregularly scheduled meeting of managers at the Utility. Indeed, these managers' meetings encompassed both formal meeting practices as well as a shared lunch. When weasked why this was the case, it was justified as follows:

He [the senior manager] purposely allows for gn hoyr and a bit lunch, because it's the informal chat, and we've learnt it over the years, sometimes the informal chat over lunch is almost more beneficial than everyone sitting there in a chair, looking at [the manager].

This consuming alongside or during work appears to be working for the organisation. Despite the stated agenda of the meeting, and nore formal meeting procedures that may prevail before and after the lunch-space, yesan see consuming, and working, and learning by people positioned between working and not working; in a space between a meeting and 'an hour and a bit lunch'. We suggest that consuming is working for the organisation and creating what we understand as a thirdspace. In the two examples immediately above, the manager initiates consuming spaces, however workers (like the council worker below) also initiate these consuming spaces alongside work - in this case at workstations:

I'mon the front, counter so if I'm on the 'phone the girls are really good...we all help each other out if she's on the phone I'll answer it if she can't get the front counter I'll get it..some days you forget to eat, some days you eat all day [giggle] I like those dax but then again I eat and work at the same time.

Here the distinction between work and non-work, work-space and social-space, and through extension, the separate identities of workers and non-workers, do not hold - the distinctions blur, and the worker's account suggest they accept these positionings unproblematically. However, not all consuming practices were physically located within the confines of the workplace. The notion of 'being allowed' to consume has become particularly pertinent with regard to the consuming of nicotine. This is seen even more clearly where consuming practices occur outside, or beyond work places. Hence, a third group of spaces we refer to here are those located outside the organisations, for example, cafes and pubs (following Oldenberg's 'places'). These places, like the tea/lunchrooms etc., are not static 'containers' where social action occurs. They do not have stable identities and, even though they have a commonly recognised identity in our social world, they, too, are subject to being reconfigured by consuming practices into thirdspaces. For example, a café is a workplace for those employed there. However, at the same time it may also be an economic space for those with 
Submitted version - not for citation. See published article at http://www.springer.com//2/AVHG3jMSAgfPWjhryHL9

commercial or economic interests, for those seated at tables it might be one of socialising with friends, or a family space, or a workspace. It is notable that despite material conditions that construct places and represent them to the world as one sort of place, they are, nevertheless, able to be reconfigured by the practices of those who occupy them. It is the practices within these places that create their meaning(s) and it is this co-existence of consuming and chatting as part of the spaces we explore in regard to researching work and learning. In our two examples below, a Council worker (then a Community College worker) describes one such space - a pub - and what goes on there. In both cases the consuming (of alcohol?) occurs beyond work, and by employees/people outside their normal working hours. While this might seem as though no work is going on, or not much worker identity is being evoked, the examples below suggest otherwise:

The carpenter would be at the pub on a Friday night and chit chat to the librory assistant who'd say, 'Oh, like, we haven't got all the shields ... at our library, and, on the Monday morning somebody would go out there and build ... shields...

I'd whinge to a mate on a Friday night over a few drinks - that's what it's alkabout, going to the pub on a Friday night whinging about someone at work-thar's how it works doesn't it? - like I mean that's how it works for a lot of people.

The first example suggests a benefit to the organisation as council work is being negotiated and planned. The second illustrates worker identities beyong the organisation in a different way. Here, through gossip, worker trust and solidarity are being established (Eggins and Slade 2004) and maintained beyond the workplace, yet these discussions are implicating relations and identities at work. Thus, in both instances the pub is reconfigured as a kind of workspace - one where identities and social relations pertaning to work are formed. The carpenter, the library assistant, and even 'the whinger' croate hybrid social/work spaces and identities. A third example can be drawn from the Utility where smokers from all sections of the organisation congregated in a designated moking space (blue squares painted on the ground in depots). The talk of the predominantly male workforce oscillates between general chat about football and fishing, to discussion of issues impacting on the various departments (e.g. transmission and distribution). Ironically, these later topics constitute the organisational integration that managers were hobing to achieve with the safety days (above). It is also a nice example of where consuming euts across hierarchies: enabling conversations between senior managers (if smokers) and workers lower in organisational hierarchies. However, not all the examples we cameacross in the data were serendipitous consuming practices. Here we want to conclude this section with some instances of managers deliberately reconfiguring spaces. In these examples, the managers purposely re-locate themselves to where 'their' workers are the lunchroom, at a physically remote work site and, in the final example, by taking workers for a drive around work sites. In these instances managers relocate into the workers' domains. The first extract is a manager from the Utility who recognises the potential of deliberatelycreating consuming spaces:

Ifind that I like to go downstairs to the lunchroom personally and have lunch, because, you come across another - a whole spectrum of other people rather than people here in the office.

A Council manager reconfigures space through purposefully going to a depot each morning and having coffee with his workers:

...why I have that coffee is because I don't see them - they're off-site so I always go there to have a cup of coffee and to chat-you know - we talk about a few things but it gives them an opportunity to talk to me.

Finally, a newly appointed manager, when asked how he learned his new role, answers:

\footnotetext{
${ }^{1}$ Colloquial for 'complain'
} 
Submitted version - not for citation. See published article at http://www.springer.com//2/AVHG3jMSAgfPWjhryHL9

... I had no idea [of how to do my job] it was very much learn as you go. Again, it's just walking around talking to people, I mean, personally I don't have too many formal meetings, I prefer to go and say 'Let's go for a drive, look at some jobs' have a chat on the way, come outside... or if they're smokers, have a smoke, whatever it may be.

Each of these managers deliberately initiates consuming practices to produce some sort of benefit for themselves, for other workers, and/or for the organisation. In essence, they create consuming spaces as a deliberate intervention to promote their own, or their workers' development. There are, however, many ways these tactics could be understood and taken up by workers involved, which we discuss below.

\section{A caution before concluding}

Eager to deflect 'conclusions' of 'if you feed them they will learn' we end this paper with examples providing a caveat against such an unhelpful stance. The extracts abovesuggest these managers are aware of the importance of building social relations in the workplace exemplified by the lunching, drinking coffee and smoking together with employees! $>$ However, Sturdy, Schwarz \& Spicer (2008 p. 929) describe these as tactical spaces, and potentially deceiving in terms of identity and authority (ibid). Many of the gxamples discussed in this paper, and particularly the extracts above can be seen from the perspective of this potential deception. The managers are deliberately creating particular relationships with subordinates foregrounding informality and friendliness that may sety un ways of being and relating that suggest an absence or levelling of hierarchy and power. The ways the consuming practices instigated by the managers are commented on demonstrates their attempts to flatten hierarchies and develop trust. Managers' tactica/deployment of consuming practices is presented by them as contributing to their own professiomal development and also contributing to the 'work' of their organisation A final vignette foregrounds the possibility that encouraging consuming practices uncritically might actually hinder the learning managers seek to promote (ANON 2009). Whilo the managers above were optimistic about their intervention, the Council example (below) signals a need for caution. By way of background, a manager implemented comptilsory 'morning teas' because, he told us, this was 'the only time [workers] can gett together'. However, along with 'getting together' he explained how morning teas served to 'value add':

...if someone has been out to a course they will give a brief talk to that team and say that's what we velearned - it won't be written and it won't be formal but that's one way of integrating what was learned back in - particularly if it's an expensive course we'th insist on getting some more value out of that cost.

This attempt to value-add', through the creation of a consuming/learning space, was problematic given the differences in how the morning teas were experienced by the very field workers 'being developed':

... We have a compulsory morning tea, believe it or not - to make people talk to each other, and it's really strange because all these people in the office that you don't know and you can't really talk to them because you're only sort of - may talk to them once a month - and I feel sorry for all the rangers standing there together-and some people mix, but not really.

In other words, it is not as simple as providing consumables, or even creating consuming spaces for learning to occur. As pointed out earlier, these spaces are socially constructed and, as such, relatings (and learning) are able to be resisted as well.

\section{Conclusion}

With our caution made, we reiterate consuming practices can hold potential for promoting learning at work: learning to know about work (knowledge), learning to do jobs 
Submitted version - not for citation. See published article at http://www.springer.com//2/AVHG3jMSAgfPWjhryHL9

(competence), learning to be (becoming) particular kinds of workers, and for learning to work together (participating). As maintained by Pina $e$ Cunha et al. (2008), 'the role of food belongs to the everyday stuff of organizational life' (p. 957), and we agree the relationship between food and the organisation is 'anything but banal' (p. 957). For us, the interest is in how the seeming banality of food and drink and their consumption - the everydayness of consuming practices - nevertheless plays an important part in work practices and workplace learning.

The language of contemporary organisations is rich with consuming metaphors where 'tightening one's belt', 'becoming leaner' and so on, results in a reduction of organisationally-created consuming and other consuming practices. This is particularly pertinent given an economic climate where organisations may feel such measures are in order if they are to survive an economic downturn. It is likely, in efforts to be leaner, consuming practices (and potential learning) may in fact decrease. Our hope is that consuming practices are kept on (at) the table. The exemplars presented here only begin to hint at the potential of these practices to do far more than provide a social event or sustenance. The possibilities and complexities of consuming practices in organisations imbue them with greater significance for organisational and workplace learning than might at first be recognised

Following Soja, acknowledging these consuming practices as ived spaces means understanding them as embodying the real and imagined lifeworld of expeniences, emotions, events and political choices. Thus, this in-between, liminal or thitdspace is one beyond both physical and mental space that offers potential for learning to know, do, be and live/work together in ways that 'normal' everyday work may not promote.

Through illustrative data from multiple york sites we have drawn attention to the relationship between consuming practices and learning as well as shown how consuming practices are in-between everyday work tasks: ones that are ostensibly in the private domain yet enacted at, alongside and even beyond work. Ourfocus has been on the potential of the 'work' done by consuming practices. The quotidian nature of consuming - as an integrated practice - has been investigated anew across a number of worksites, providing a fresh lens on where, how, with whom and in what circumstances this practice is linked to specialized work. While our introduction to the paper began by differentiating consuming from specialised work as integrated and dispersed practices respectively, we arrive at a conclusion where their 'bundling' (Schatzki 2006) together has shown itself to be significant for identifying learning. Our discussions invite a critical look at the possibilities of consuming practices for fostering important learning relationships for both individual workers and their organisations. We believe failure to redognise the potential of these practices can result in lost opportunities for fully understanding learning at work and consequently underestimating their relevance for research on workplace learning.

\section{References}

Bhabha, K.K. (1994). The location of culture, Routledge, London.

ANON. (2009).

Brewis, J. \& Grey, C. (2008). The regulation of smoking at work, Human Relations, vol. 61, no. 7 , pp. $965-87$.

Billett, S. (2001). Learning through work: workplace affordances and individual engagement, Journal of Workplace Learning, vol. 13, no. 5, pp. 209-14.

Billett, S. (2011) Workplace curriculum: practice and propositions, in F. Dochy, M. Gijbels \& P. van den Bossche (eds), Theories of learning for the workplace: building blocks for training and professional development programs, Routledge, Milton Park, Abingdon, Oxon, pp. 17-36. 
Submitted version - not for citation. See published article at http://www.springer.com//2/AVHG3jMSAgfPWjhryHL9

Briner, R. \& Sturdy, A. (2008). Introduction to food, work and organization, Human Relations, vol. 61, no. 7, pp. 907-12.

Delors, J. (1996). Learning: the treasure within - Highlights: A report to UNESCO of the International Commission on Education for the Twenty-first Century, UNESCO, Hamburg.

du Gay, P. (1996). Consumption and identity at work. London: Sage.

Edwards, R. \& Usher, R. (Eds) (2000). Globalisation and Pedagogy: Space, Place and Identity, Routledge, London.

Eggins, S. \& Slade, D. (2004). Analysing casual conversation, Continuum, London.

Engeström, Y. (2001). Expansive learning at work: toward an activity theoretical reconceptualization, Journal of Education and Work, vol. 14, no. 1, pp. 133-56.

Fenwick, T., Edwards, R. \& Sawchuck, P. (2011). Emerging approaches to educational research: tracing the socio-material, Routledge, Milton Park, Abingdon.

Fenwick, T. \& Field, J. (2014). Introduction of the visible and invisible inwork and learning, Journal of Workplace Learning, vol. 26, no. 6/7.

Flores-Pereira, M., Davel, E. \& Cavedon, N. (2008). Drinking beerand understanding organizational culture embodiment, Human Relations, vol. 61, no. 7, pp. 1007-26.

Flowers, R. \& Swan, E. (2012). Pedagogies of doing good: problematisations, authorities, technologies and teleologies in food activism, Austratian Journal of Adult Learning, vol. 52, no. 3, pp. 532-72.

Friedman, M. (1957). A Theory of the Consumption: prondeton university press Princeton, NJ.

Gherardi, S. (2001). From organizational learning to practice-based knowing, Human Relations, vol. 54, no. 1, pp. 131-9.

Gherardi, S. (2006). Organizational Khomledge: The Texture of Workplace Learning, 2nd edn, Blackwell, London.

Gherardi, S. (2009). Knowing and learning in practice-based studies: an introduction, Learning Organization, voly 16, no. 5, pp. 352-9.

Hager, P. \& Hodkinson, P. (2011). Becoming as an appropriate metaphor for understanding professional learning, in L. Scanion (ed.), Becoming" a professional: an interdisciplinary analysis of professional learning, Springer Science+Business Media, Dordrecht Heidelberg London New York, pp. 33-56.

Hager, P. (2008).Learning and metaphors, Medical Teacher, no. 30, pp. 679-86.

Harbers, H, Mol, A. P. J., \& Stollmeyer, A. (2002). Arguments for an ethnography of daily care. Theory, Culture \& Society, 19(5/6), 207-226.

Heaton, J. (2008). Secondary analysis of qualitative data, in P. Alasuutari, L. Bickman \& J. Brannen (Eds), The handbook of social research methods, Sage, London, pp. 506-19.

Hopwood, N. (2014). Four essential dimensions of workplace learning, Journal of Workplace Learning, vol. 26, no. 6/7, pp. 349-63.

ANON (2012).

ANON (2013).

Kemmis, S. (2009). Understanding Professional Practice: A Synoptic Framework, in B. Green (ed.), Understanding and Researching Professional Practice, Sense Publishers, Rotterdam, pp. 19-38. 
Submitted version - not for citation. See published article at http://www.springer.com//2/AVHG3jMSAgfPWjhryHL9

Keynes, J. M., \& Moggridge, D. E. (1979). The general theory and after: a supplement. London: Macmillan for the Royal Economic Society.

Morris, D. (2005). It's a sprawl world after all: The human cost of unplanned growth - and visions of a better future, New Society Publishers, Limited, Gabriola Island, BC, Canada.

Oldenburg, R. (1999). The great good place: cafes, coffee shops, bookstores, bars, hair salons, and other hangouts at the heart of the community, 3rd edn, Marlowe \& Company, New York, New York.

Parker, M. (2008). Eating with the Mafia: belonging and violence, Human Relations, vol. 61, no. 7, pp. 989-1006.

Pina $e$ Cunha, M., Cabral-Cardoso, C. \& Clegg, S. (2008). Manna from heaven: the exuberance of food as a topic for research in management and organization, Human Relations, vol. 61, no. 7, pp. 935-63.

ANON (2006).

ANON (2006).

ANON (2014).

Schatzki, T.R. (1996). Social practices:A Wittgensteinian approach tolyuman activity and the social, Cambridge University Press, Cambridge.

Schatzki, T.R. (2005). The sites of organizations', Organization Studies, vol. 26, no. 3, pp. $465-84$

Schatzki, T.R. (2006). On organizations as they happen. Organization Studies, vol. 27, no. 12, pp. 1863-73.

Sfard, A. (1998). On two metaphors for learning and the dangers of choosing just one', Educational Researcher, vol. 27 no. 2, pp. 4-13.

Shove, E, Trentmann, F, \& Wilk, R(Eds). (2009). Time, consumption and everyday life: practice, materiality and Calture Oxford and New York: Berg Publishers.

Soja, E. (1996). Thirdspace, Soumeys to Los Angeles and other real-and-imagined places, Blackwell Publishers Ltd!, Malden, Massachusetts.

Soja, E. (2001). Postmodern geographies: the reassertion of space in social critical theory, Verso, London.

ANON (2006)

Sturdy, A. Schwarz, M. \& Spicer, A. (2008). Guess who's coming to dinner? Structures and uses of liminality in strategic management consultancy, Human Relations, vol. 59, no. 7, pp. 929-60.

Warner, A., Callaghan, E. \& de Vreede, C. (2013). Promoting sustainable food and food citizenship through an adult education leisure experience, Leisure/Loisir, vol. 37, no. 4, pp. 337-60. 